\title{
The trans-Eurasian crop exchange in prehistory: discerning pathways from barley phylogeography
}

Huw Jones ${ }^{1}$, Diane L. Lister ${ }^{2}$, Dawei Cai ${ }^{3}$, Catherine J. Kneale², James Cockram¹, Leonor Peña-Chocarro ${ }^{4}$, Martin K. Jones ${ }^{2}$

${ }^{1}$ National Institute of Agricultural Botany (NIAB), Huntington Road, Cambridge, CB3

OLE, UK

${ }^{2}$ McDonald Institute for Archaeological Research, University of Cambridge, Downing Street, Cambridge, CB2 3ER, UK

${ }^{3}$ Ancient DNA Laboratory, Research Center for Chinese Frontier Archaeology of Jilin University, Changchun 130012, China

${ }^{4}$ Escuela Española de Historia y Arqueología, Consejo Superior de Investigaciones Científica, Via di Torre Argentina 18, 3º, 00186 Roma, Italia

\section{Corresponding author:}

Huw Jones

Address: NIAB, Huntington Road, Cambridge, CB3 OLE, UK

Email: huw.jones@niab.com

Tel: +44 1223342200

\begin{abstract}
A number of crops that are of global importance today, including wheat (Triticum spp) and barley (Hordeum vulgare), were domesticated in Southwest Asia between 10,000 and 11,000 years ago and subsequently spread through the Old World, into Europe, North Africa and eastwards across Eurasia. Their routes of expansion have been a focus of debate and are increasingly being revealed by widespread dating of archaeobotanical remains from across Eurasia. Of particular interest is work by Zhao (2009) who proposed three routes for the spread of wheat into China: firstly, across the Eurasian Steppe, second by sea from India to the east coast of Eurasia and third, along the Hexi Corridor, which
\end{abstract}


forms part of the Silk Road in western China. Molecular genetic analysis of cereal landraces have also elucidated routes of expansion of cereal cultivation and, in addition, have revealed how crops adapted to changing environments as they moved away from their centres of domestication. Genes involved in flowering time genes have been a particular focus of these studies, including the photoperiod response gene Ppd-H1 in barley, which controls flowering in response to increasing day-lengths in the spring. In this paper we present a phylogeographic analysis of Old World landrace and wild barley, through the analysis of a portion of the Ppd-H1 DNA sequence. We discuss the geographic distribution of different haplotypes of this gene across Eurasia in the light of Zhao (2009)'s three routes and what it potentially reveals about trans-Eurasian pathways of contact between early farming communities.

\section{Keywords}

Barley; flowering time; photoperiod response; domestication; agricultural spread; phylogeography

\section{Introduction}

A number of crops domesticated in southwest Asia between 10,000 and 11,000 years ago have now become global crops of significant economic importance; these include wheat (Triticum spp.) and barley (Hordeum vulgare). During prehistory, these two crops spread through the Old World, into Europe, North Africa and eastwards across Eurasia, while at a similar time other cereal domesticates originating in China (Panicum miliaceum and Setaria italica) spread towards the west (Jones et al., 2011a). The routes of expansion of these southwest Asian crops, and by implication the networks of contact between prehistoric farming communities, has been a focus of debate (e.g. Fuller, 2011a, b; Jones et al., 2011a; Spengler et al., 2014; Zhao, 2009). Widespread recovery of archaeobotanical remains using flotation at many archaeological sites across Eurasia and accurate radiocarbon dating of single grains has revealed an increasingly detailed picture of how and when crops reached particular regions and the routes by which they spread. Determining how crops adapted to novel environments as they were moved from centres 
of domestication in also informative. In the past decade a number of phylogeographic studies of extant crop landraces have also sought to address these questions, many with a particular focus on genes involved in flowering time determination, for example vernalization and photoperiod response genes in wheat and barley (e.g. Cockram et al., 2011; Jones et al., 2008; Kippes et al., 2015; et al., 2007; Saisho et al., 2011).

Archaeological evidence from the Near East shows that wild barley was being utilized for at least 10,000 years before morphological domestication (Hillman et al., 2001; Weiss et al., 2004). Non-brittle two-rowed (i.e. domesticated) barley has been identified at Near Eastern sites such as Tell Abu Hureyra in the early 9th millennium BC; (Hillman, 1975) and Tell Aswad in the 8th millennium BC (van Zeist and Bakker-Heeres, 1985). Nonbrittle six-rowed barley has been identified at Ali Kosh, Iran, in the 8th millennium BC. Records of naked barley, mostly from six-rowed forms, appear at Ali Kosh from the 7th millennium BC (Helbaek, 1969). By the beginning of the third millennium BC, wheat and barley had spread across the Old World, and were being cultivated in Europe, North Africa and eastwards into South Asia and China (Helbaek, 1969; Jones et al., 2013; Jones et al., 2012; Jones et al., 2011a; Zohary and Hopf, 2000). Much of the literature has focused on the spread of wheat species, since this grain is predominates in the archaeobotanical records of the period. However, barley is frequently found alongside wheat in archaeobotanical assemblages in the Old World; two Southwest Asian staples travelled together as part of the 'Neolithic package' which also included sheep (Barker, 1985).

Evidence for the arrival of the southwest Asian cereals in North Africa is quite sparse, with flotation and dating of archaeobotanical remains occurring only recently. Morales et al. (2013) suggest that the similarity in radiocarbon dates in domesticated plant species from Neolithic sites in North Africa and the Iberian Peninsula is evidence for synchronous spread of agriculture along both shores of the western Mediterranean, where barley dates from the $7^{\text {th }}$ millennium BP.

Barley cultivation reached China by 4,500 BP (Flad et al., 2010), and was found at altitudes of at least 3,600 $\mathrm{m}$ in the Tibetan Plateau by 3,500 BP (Chen et al., 2015). 
During the 3rd millennium BC barley is recorded in Korea (Crawford and Lee, 2003) and middle Jomon Japan (Matsui and Kanehara, 2006). With flotation and advances in AMS radiocarbon dating technologies, it has been possible to directly date archaeological cereal remains. Such data led Zhao (2009) to propose three different routes for the spread of wheat (and by inference barley) into China around 4,000 BP:

(1) The Eurasian Steppe Route, in which wheat (and other southwest Asian package items including barley and sheep) spread to China by means of the vast steppe traversing Central Asia, southern Siberia and the Mongolian highlands. Archaeological evidence lends support to Zhao's (2009) northern steppe route accounting for contact between east and west Eurasia, and a pathway of movement of resources and ideas about horse-riding, sheep herding, metal technology (Chernykh, 2008) and the farming of such cold hardy crops as barley. The latitude of such a steppe route would be expected to involve cereals non-responsive to increasing daylengths in the summer, as will be discussed below, and lead to shared genetic patterns from west to east.

(2) The Sea Route, where wheat spread into China by boat from South and Southeast Asia. Wheat was a major crop of the Indus Civilization by this time (Constantini, 1984). At the time Zhao's paper was written, the earliest dated wheat was found in Shandong and Fujian Provinces, on the east coast of China; more dates have now indicated that the earliest dates for wheat are inland in Gansu Province (Dodson et al., 2013). Betts et al. (2014) consider this coastal route unlikely as it would take the western cereals through landscapes and climates not suitable for their cultivation.

(3) The Silk Road, where wheat was introduced into China along the Hexi Corridor, which during historical periods became an important route between Central Asia and North China. This is topographically the most convenient route East-West and it is highly likely that this route was used during prehistory as well, with many of the earliest dated wheat remains come from this region (Betts et al., 2014). 
In practice, there may have been a combination of different routes. The initial hypotheses of Zhao (2009) allow us to support or challenge some of the potential routes in the spread of the Southwest Asian crops through Eurasia.

Archaeological and archaeobotanical data pertaining to the domestication of crops and the spread of agriculture is being supplemented with molecular genetic data derived from living cereal landraces and wild progenitors (e.g. Poets et al., 2015; Saisho and Purugganan, 2007), from herbarium specimens (e.g. Lister et al., 2009) and, more rarely, from archaeological material (Li et al., 2011; Smith et al., 2015). These studies are revealing the locations and number of domestication events, the identity and function of 'domestication genes', such as those determining the brittle/tough rachis trait, as well as how and by what routes cereals spread from their centres of domestication. Various reports have argued that barley was domesticated more than once and in different areas, and that domesticates from each area spread via different trajectories (e.g. Morrell and Clegg, 2007; Saisho and Purugganan, 2007). Different types of genetic markers have been used in phylogeographic studies; e.g. analysis of neutral markers such as microsatellites, or simple sequence repeats (SSRs), have revealed population structure relating to the spread of agriculture across Europe and North Africa (e.g. Jones et al., 2013; Jones et al., 2012; Jones et al., 2011b; Oliveira et al., 2012) and the analysis of single nucleotide polymorphisms (SNPs) in expressed genes has aided in our understanding of how, for example, crops adapt to novel environments by modifications to flowering-time pathways (Jones et al., 2008).

\subsection{The role of environmental adaptation in the spread of agriculture}

During prehistory barley cultivation spread into climatically novel environments, ranging from cold temperate regions of northern Eurasia to sub tropical regions of South Asia, and high altitude regions of the Tibetan Plateau. In order that plants may complete their life cycle it is essential that flowering coincides with favourable seasonal conditions, enabling plants to avoid damage through extremes of temperature or drought (Cockram et al., 2007). Work by various authors has shown that variants in different genes involved in flowering time have been important in the adaptation of barley to novel environments. 
These genes in wheat and barley include those involved in photoperiod response, (e.g Ppd-H1) in which flowering is triggered in response to long days (e.g. Jones et al., 2008; Turner et al., 2005), and vernalization, where flowering is initiated after a period of chilling in the vegetative state, e.g. Vrn1, (Yan et al., 2003) and Vrn2 (Yan et al., 2004). Understanding the ecological drivers of cereal cultivation and successful completion of lifecycle (i.e. flowering and seed set) is an important factor in understanding patterns of agricultural spread.

The Ppd-H1 gene has been the subject of previous research by Jones et al. (2008) on European landrace barley and Near Eastern wild barleys, and Stracke et al. (2009) on a set of world-wide barleys. Analysis of the Ppd-H1 gene by Jones et al. (2008) identified the causal single nucleotide polymorphism (SNP) that turns off the trigger to flower in response to long days, and the distribution of the wild type and mutant form shows a geographic cline, with a predominance of non-responsive forms in northern latitudes (also see Lister et al., 2009). Switching-off the promotion of flowering in response to long days is seen to be an adaptation to temperate climates, where there is no summer drought and so it is advantageous for the plant to build biomass and flower later in the growing season. The greater DNA sequence diversity in the Ppd-H1 gene among European barley landraces has revealed phylogeographic patterns that may be compared with the different dispersals of agriculture into Europe during the Neolithic, as indicated by pottery typologies and archaeobotanical evidence (Jones et al., 2013; Jones et al., 2012).

In this study we have looked at a smaller region within the $P p d-H 1$ gene studied by Jones et al. (2008), in a set of 510 well-provenanced barley landraces from across the Eurasian continent, including the European accessions previously analysed by Jones et al. (2008), barley landraces from North Africa, and a set of 72 Near Eastern wild barleys. Analysis of sequence data revealed phylogeographic patterning in the spatially distributed set of landraces across Eurasia. The geographical patterns of $\mathrm{Ppd}-\mathrm{H1}$ haplotypes presented here allows us to discriminate between various routes of spread of Old World barley, away from its ancestral agricultural habitat to regions of the world with distinct seasonal 
challenges, and in the process cast light on the interconnections between the human communities mediating that movement.

\section{Materials and methods}

\subsection{Plant materials}

A set of $582 \mathrm{H}$. vulgare accessions from diverse collection sites including $510 \mathrm{H}$. vulgare ssp vulgare landraces from 60 countries and $72 \mathrm{H}$. vulgare ssp. spontaneum accessions from 14 countries was assembled from seven international germplasm collections. Where the information was available, the accessions' sub-species, collection site (description, latitude and longitude), and germplasm collection references were collated (Table S1). For those accessions with a collection site description only, geographic coordinates were abstracted from National Geospatial-Intelligence Agency (USA) on-line databases available at https://www1.nga.mil (Jones et al., 2008).

\subsection{Genotyping and sequence analysis}

The 1,230 bp Ppd-H1 genomic amplicon described by Stracke et al. (2009) spanning the causal SNP, as determined by Jones et al. (2008), was re-sequenced following the methods described by Jones et al. (2008). Sequence traces were compiled and edited using the ContigExpress module within Vector NTI Advance v10.1.1 (Invitrogen), allowing identification of polymorphisms. The haplotype diversity $(\mathrm{H})$ is computed as:

$$
H=\left(\frac{N}{N-1}\right)\left(1-\sum_{i=0}^{N} x^{2}\right) \text { where } \mathrm{x}_{\mathrm{i}} \text { is the frequency of each haplotype in the sample of }
$$

size $\mathrm{N}$.

The relationships among haplotypes were described graphically using Network (Forster et al., 1996). Where accessions were organised into novel haplotypes, they were grouped by reference to the haplotype with the least mutational distance from the novel haplotype. Ppd-H1 sequence variation for 194 of the landraces and all of the wild barley accessions is previously described in Jones et al. (2008) (Table S2). 


\section{Results}

We identified 29 Ppd-H1 SNPs among the 582 wild and landrace barley accessions analysed (Table S1). Of these, 21 had been previously observed among European accessions (Jones et al., 2008). The majority of polymorphisms (16 out of 29) represented rare events, having minor allele frequencies (MAFs) of $<0.05$. Polymorphisms were organised into 58 haplotypes, of which 31 had more than one member (Table 1). The majority of landrace accessions (442 out of 510) were organised into eight 'frequent haplotypes' ( $\geq 10$ members). Haplotype diversity among the landrace accessions was 0.89 . The wild barley accessions were organised in 30 haplotypes with a haplotype diversity of 0.93 , and 39 haplotypes were observed within landrace haplotypes (haplotype diversity $=0.87)$ (Table 1$)$. Nineteen haplotypes included wild barley accessions only, while 29 haplotypes were private to the landraces. Haplotype diversity of each of the frequent haplotypes is shown in Table 1. The relationships among haplotypes are illustrated using Network software (Forster et al., 1996) in Fig. 1. The haplotype network produced is similar to that reported in Jones et al. (2008), but less well resolved, which would be expected from sequencing a smaller gene fragment. The wild barley accessions occupy central positions within the network, with a group at the top of the network solely consisting of wild barley accessions (Fig. 1).

Within the landraces, the majority of accessions are accounted for by eight 'frequent' haplotypes, A to H, each of which occupy distinct geographic regions within the total geographic area sampled (Fig. 2; Table S2). Haplotypes A and B solely consists of

photoperiod non-responsive landraces and wild barleys predicted from the causative SNP, where there is a ' $\mathrm{T}$ ' nucleotide instead of a ' $\mathrm{C}$ ' at position $2423 \mathrm{bp}$, as described by Jones et al. (2008). Haplotype A has 65 members and a broad geographical distribution, occurring in Turkey, Iran, the Caucasus through Central Asia and the Himalayas to northern and eastern China. One accession is present in each of Hokkaido and the Kiril Islands. Haplotype B has 85 members and, with a few exceptions in eastern and central regions of the former USSR, is confined to Europe. Haplotype C has 109 members and has the most expansive east-west distribution (from the Canary Islands to Honshu, Japan) predominantly in the southern part of the North Temperate Zone and is the most common 
haplotype in the Chinese Tibetan Plateau. Haplotype D has 38 members and is confined to southern and western Asia, from Turkey in the west, through Syria, Iraq and Iran, to the Indian sub-continent, where it is the most common haplotype. One accession occurs in central China. Haplotype E has 44 members and is confined to Europe. Haplotype F has 22 members and is sparsely distributed in North Africa, the Levant, the Caucasus and Central Asia, with one accession in India, and is absent from Europe and China. Haplotype G has 68 members in Iran, Afghanistan and Pakistan, further east in China and Korea, and in Japan where it is the most numerous haplotype. Haplotype H has 11 members and a very restricted range: it is present in Iran, Afghanistan and Pakistan, with one individual in India.

\section{Discussion}

We have analysed the phylogenetic relationships between different Near Eastern wild, and Eurasian and North African landrace barley using partial sequences of the Ppd-H1 gene, and the resulting haplotype structure is revealed using Network software (Fig. 1). Compared to the previous study by Jones et al. (2008), the discrimination between haplogroups is reduced, as may be expected from the reduction in the length of sequence considered (3,508 bp vs. 1,230 bp).

The accessions that harbour the mutant photoperiod non-responsive $p p d-H 1$ allele fall into two distinct haplotypes (A and B), that includes both landraces and wild barley accessions. As mentioned above, non-responsive forms of $p p d-H 1$ have an adaptive significance in northerly European latitudes. Significantly, the clear east-west divide of the two haplotypes of non-responsive barleys indicates independent spread, and thus argues against a northerly steppe route as accounting for the spread of barley eastwards across Eurasia.

The remaining haplotypes reflect different aspects of the global spread of barley. Haplotype E reflects the well attested European spread of Neolithic agriculture also discernible in haplotype B. We may add that $\mathrm{E}$ also has a northerly distribution mirroring $\mathrm{B}$, and speculate that members of E may display an appropriate adaptive trait at other 
gene loci, such as those determining a vernalization requirement (Vrn genes), for example (Cockram et al., 2007). Haplotypes D and H correspond with a well attested early expansion of barley agriculture from south west Asia to the Indus Valley, recorded at the site of Mehrgarh in the 7th millennium BC (Constantini, 1984). Haplotype G has a more easterly distribution, and of all the common haplotypes could be the most resonant with a coastal route, linking South Asia with the eastern Chinese coastline, along with Korea and Japan. Archaeobotanical evidence indicates the appearance of barley in Japan during the 1st millennium BC (Matsui and Kanehara, 2006), suggesting such a coastal route was a significantly later episode than others discussed in this section. Archaeological evidence from trade in glass beads suggests contacts by coastal routes between northern India and South East Asia were well established by 500 BC (Carter, 2010; Lankton and Dussubieux, 2013). Three haplotypes, A, C and F, have geographic distributions consistent with crop dispersal through a Central Asian corridor.

Of Zhao (2009)'s proposed three routes for the spread of the southwest Asian cereals into east Asia, one of the geographical patterns of the eight common haplotypes accommodates a potential sea route quite late in the sequence, and accounting for a number of barleys bordering the China Sea, but the common haplotypes do not easily accommodate a northerly steppe route.

Four of the remaining seven common haplotypes (and also the coastal haplotype $G$ ) are photoperiod responsive types of $\mathrm{Ppd}-\mathrm{H} 1$ and are confined below the $40^{\circ} \mathrm{N}$ parallel (a rough proxy for freedom from recurrent winter frosts). Of these, $\mathrm{E}$ is predominantly a western haplotype, while haplotypes $C$ and D have significant eastern spreads. However these two eastern spreads have distinct geographies, C predominating in East Asia, D in South Asia. This suggests independent eastward movements into these two regions, rather than a direct flow between the two.

The remaining option is that which Frachetti (2012) describes as an 'Inner Asia mountain corridor', which Frachetti applies to the Pamir, Tian Shan and Altai ranges, but we can extend here to embrace other fertile ranges associated with the Himalayan uplift. This would provide a circulation space for higher altitude photoperiod responsive and non- 
responsive barleys, pre-adapted to independent spread into the frost-affected northern latitudes of the east and west, and lower altitude responsive barleys to spread to more southerly parts of China. Mobile Eurasian pastoralists cultivating various crops including wheat and barley are thought to be responsible for the introduction of these crops into China.

The proposed sequence is thus as follows:

(1) Multiple domestications in South West Asia, with distinctive persistent signatures for 'eastern' and ‘western' region domestications, as previously observed by a number of authors (Morrell and Clegg, 2007; Poets et al., 2015; Saisho and Purugganan, 2007). Hybridisation between 'western' landraces and 'eastern' wild barley contributed to these domestications. This would also involve within region circulation of landraces from eastern and western wild barley populations.

(2) Early expansion of barley westwards into the Mediterranean and eastwards into central Asia as reflected by haplotypes C and F. Separate expansion south-westwards into Baluchistan and Indus Catchment, as reflected by haplotype $\mathrm{H}$, and subsequent spread across South Asia, as reflected by haplotype D. Movement of non-responsive haplotype B into northern Europe and beyond (a movement mirrored by haplotype E, suggestive of adaptive traits at other loci)

(3) A third to second millennium BC circulation of cereals along foothills associated with Inner Asian mountain ranges, reflected in haplotypes A, C and F.

(4) 1st millennium AD coastal movement of barley along maritime China, Korea and Japan, as reflected by haplotype G, and broadly coeval movement from the mainland of non-responsive A haplotypes into Hokkaido and the Kuril islands.

\section{Acknowledgements}


This research was conducted under the auspices of the 'Food Globalization in Prehistory'

(FOGLIP, 249642) and 'Origins and Spread of Agriculture in the South West

Mediterranean Region' (AgriWestMed, 230561) research projects, both funded by the

European Research Council.

\section{References}

Barker, G., 1985. Prehistoric Farming in Europe. Cambridge University Press, Cambridge.

Betts, A., Jia, P.W., Dodson, J., 2014. The origins of wheat in China and potential pathways for its introduction: A review. Quaternary International 348, 158-168.

Carter, A., 2010. Trade and exchange networks in Iron Age Cambodia: preliminary results from a compositional analysis of glass beads. Bulletin of the Indo-Pacific Prehistory Association 30, 178-188.

Chen, F.H., Dong, G.H., Zhang, D.J., Liu, X.Y., Jia, X., An, C.B., Ma, M.M., Xie, Y.W., Barton, L., Ren, X.Y., Zhao, Z.J., Wu, X.H., Jones, M.K., 2015. Agriculture facilitated permanent human occupation of the Tibetan Plateau after 3600 BP. Science 347, 248250.

Chernykh, E., 2008. Formation of the Eurasian "Steppe Belt" of stockbreeding cultures: viewed through the prism of archaeometallurgy and radiocarbon dating. Archaeology, Ethnology and Anthropology of Eurasia 35, 36-53.

Cockram, J., Jones, H., Leigh, F.J., O'Sullivan, D., Powell, W., Laurie, D.A., Greenland, A.J., 2007. Control of flowering time in temperate cereals: genes, domestication, and sustainable productivity. Journal of Experimental Botany 58, 1231-1244.

Cockram, J., Jones, H., O'Sullivan, DM, 2011. Genetic variation at flowering time loci in wild and cultivated barley. Plant Genetic Resources 9, 264-267.

Constantini, L., 1984. The beginning of agriculture in the Kachi Plain: The evidence of Mehrgarh., in: Allchin, B. (Ed.), Proc. 6th Int. Conf. Assoc. South Asian Archaeologists in Western Europe. Cambridge University Press., pp. 29-33.

Crawford, G.W., Lee, G.A., 2003. Agricultural origins in the Korean peninsula. Antiquity 77, 87-95.

Dodson, J.R., Li, X., Zhou, X., Zhao, K., Sun, N., Atahan, P., 2013. Origin and spread of wheat in China. Quaternary Science Reviews 72, 108-111.

Flad, R., Li, S., Wu, X., Zhao, Z., 2010. Early wheat in China: Results from new studies at Donghuishan in the Hexi Corridor. Holocene 20, 955-965.

Forster, P., Harding, R., Torroni, A., Bandelt, H., 1996. Origin and evolution of native American mtDNA variation: a reappraisal. Am J Hum Genet. 59.

Frachetti, M.D., 2012. Multiregional Emergence of Mobile Pastoralism and Nonuniform Institutional Complexity across Eurasia. Current Anthropology 53, 2-38.

Fuller, D.Q., 2011a. Finding Plant Domestication in the Indian Subcontinent. Current Anthropology 52, S347-S362.

Fuller, D.Q., 2011b. Pathways to Asian Civilizations: Tracing the Origins and Spread of Rice and Rice Cultures. Rice 4, 78-92. 
Helbaek, H., 1969. Plant collecting, dry-farming, and irrigation agriculture in prehistoric Deh Luran. In: Prehistory and human ecology of the Deh Luran., in: Hole, F., al., e. (Eds.), Prehistory and human ecology of the Deh Luran Plain. Memoirs of the Museum of Anthropology University of Michigan, pp. 383-426.

Hillman, G., Hedges, R., Moore, A., Colledge, S., Pettitt, P., 2001. New evidence of Lateglacial cereal cultivation at Abu Hureyra on the Euphrates. Holocene 11, 383-393. Hillman, G.C., 1975. The plant remains at Tell Abu Hureyra: A preliminary report. . Proc. Prehist. Soc. 41, 70-73.

Jones, G., Charles, M.P., Jones, M.K., Colledge, S., Leigh, F.J., Lister, D.A., Smith, L.M.J., Powell, W., Brown, T.A., Jones, H., 2013. DNA evidence for multiple introductions of barley into Europe following dispersed domestications in Western Asia. Antiquity 87, 701-713.

Jones, G., Jones, H., Charles, M.P., Jones, M.K., Colledge, S., Leigh, F.J., Lister, D.A., Smith, L.M.J., Powell, W., Brown, T.A., 2012. Phylogeographic analysis of barley DNA as evidence for the spread of Neolithic agriculture through Europe. Journal of Archaeological Science 39, 3230-3238.

Jones, M., Hunt, H., Lightfoot, E., Lister, D., Liu, X., Motuzaite-Matuzeviciute, G., 2011a. Food globalization in prehistory. World Archaeology 43, 665-675.

Jones, H., Civan, P., Cockram, J., Leigh, F.J., Smith, L.M.J., Jones, M.K., Charles, M.P., Molina-Cano, J.-L., Powell, W., Jones, G., Brown, T.A., 2011b. Evolutionary history of barley cultivation in Europe revealed by genetic analysis of extant landraces. Bmc Evolutionary Biology 11.

Jones, H., Leigh, F.J., Mackay, I., Bower, M.A., Smith, L.M.J., Charles, M.P., Jones, G., Jones, M.K., Brown, T.A., Powell, W., 2008. Population-based resequencing reveals that the flowering time adaptation of cultivated barley originated east of the fertile crescent. Molecular Biology and Evolution 25, 2211-2219.

Kippes, N., Debernardi, J.M., Vasquez-Gross, H.A., Akpinar, B.A., Budak, H., Kato, K., Chao, S., Akhunov, E., Dubcovsky, J., 2015. Identification of the VERNALIZATION 4 gene reveals the origin of spring growth habit in ancient wheats from South Asia. Proceedings of the National Academy of Sciences of the United States of America 112, E5401-E5410.

Lankton, J., Dussubieux, L., 2013. Early Glass in Southeast Asia, in: Janssens, K. (Ed.), Modern Methods for Analysing Archaeological and Historical Glass. Wiley \& Sons Ltd., pp. 415-443.

Li, C., Lister, D.L., Li, H., Xu, Y., Cui, Y., Bower, M.A., Jones, M.K., Zhou, H., 2011. Ancient DNA analysis of desiccated wheat grains excavated from a Bronze Age cemetery in Xinjiang. Journal of Archaeological Science 38, 115-119.

Lister, D.L., Thaw, S., Bower, M.A., Jones, H., Charles, M.P., Jones, G., Smith, L.M.J., Howe, C.J., Brown, T.A., Jones, M.K., 2009. Latitudinal variation in a photoperiod response gene in European barley: insight into the dynamics of agricultural spread from 'historic' specimens. Journal of Archaeological Science 36, 1092-1098.

Matsui, A., Kanehara, M., 2006. The question of prehistoric plant husbandry during the Jomon Period in Japan. World Archaeology 38, 259-273.

Morales, J., Perez-Jorda, G., Pena-Chocarro, L., Zapata, L., Ruiz-Alonso, M., Antonio Lopez-Saez, J., Linstaedter, J., 2013. The origins of agriculture in North-West Africa: 
macro-botanical remains from Epipalaeolithic and Early Neolithic levels of Ifri Oudadane (Morocco). Journal of Archaeological Science 40, 2659-2669.

Morrell, P.L., Clegg, M.T., 2007. Genetic evidence for a second domestication of barley (Hordeum vulgare) east of the Fertile Crescent. Proceedings of the National Academy of Sciences of the United States of America 104, 3289-3294.

Oliveira, H.R., Campana, M.G., Jones, H., Hunt, H.V., Leigh, F., Redhouse, D.I., Lister, D.L., Jones, M.K., 2012. Tetraploid wheat landraces in the Mediterranean basin: taxonomy, evolution and genetic diversity. PloS one 7, e37063.

Poets, A.M., Fang, Z., Clegg, M.T., Morrell, P.L., 2015. Barley landraces are characterized by geographically heterogeneous genomic origins. Genome Biology 16.

Saisho, D., Ishii, M., Hori, K., Sato, K., 2011. Natural Variation of Barley Vernalization Requirements: Implication of Quantitative Variation of Winter Growth Habit as an Adaptive Trait in East Asia. Plant and Cell Physiology 52, 775-784.

Saisho, D., Purugganan, M.D., 2007. Molecular phylogeography of domesticated barley traces expansion of agriculture in the Old World. Genetics 177, 1765-1776.

Smith, O., Momber, G., Bates, R., Garwood, P., Fitch, S., Pallen, M., Gaffney, V., Allaby, R.G., 2015. Sedimentary DNA from a submerged site reveals wheat in the British Isles 8000 years ago. Science 347, 998-1001.

Spengler, R.N., III, Frachetti, M.D., Domani, P.N., 2014. Late Bronze Age agriculture at Tasbas in the Dzhungar Mountains of eastern Kazakhstan. Quaternary International 348, 147-157.

Stracke, S., Haseneyer, G., Veyrieras, J.-B., Geiger, H.H., Sauer, S., Graner, A., Piepho, H.-P., 2009. Association mapping reveals gene action and interactions in the determination of flowering time in barley. Theoretical and Applied Genetics 118, 259273.

Turner, A., Beales, J., Faure, S., Dunford, R.P., Laurie, D.A., 2005. The pseudo-response regulator Ppd-H1 provides adaptation to photoperiod in barley. Science 310, 10311034.

van Zeist, W., Bakker-Heeres, J.A.H., 1985. Archaeological studies in the Levant. 1. Neolithic sites in the Damascus basin: Aswad, Ghoraifé, Ramad. . Palaeohistorica 24, 165-256.

Weiss, E., Wetterstrom, W., Nadel, D., Bar-Yosef, O., 2004. The broad spectrum revisited: Evidence from plant remains. Proceedings of the National Academy of Sciences of the United States of America 101, 9551-9555.

Yan, L., Loukoianov, A., Tranquilli, G., Helguera, M., Fahima, T., Dubcovsky, J., 2003. Positional cloning of the wheat vernalization gene VRN1. Proceedings of the National Academy of Sciences of the United States of America 100, 6263-6268.

Yan, L.L., Loukoianov, A., Blechl, A., Tranquilli, G., Ramakrishna, W., SanMiguel, P., Bennetzen, J.L., Echenique, V., Dubcovsky, J., 2004. The wheat VRN2 gene is a flowering repressor down-regulated by vernalization. Science 303, 1640-1644.

Zhao, Z., 2009. Eastward spread of wheat into China - new data and new issues. Chinese Archaeology 9, 1-9.

Zohary, D., Hopf, M., 2000. Domestication of Plants in the Old World, 3rd edition. Oxford University Press, Oxford. 


\section{Figure and Table Legends}

Table 1: Ppd-H1 haplotype diversity among the wild barley accessions and barley landraces of the Old World and haplotype diversity for each of the frequent haplotypes described by Fig. 1. The haplotype diversity calculation is described in section 2.2.

Fig. 1: Network showing Ppd-H1 haplotype relationships among the barley landraces (grey) and wild barley accessions (black). Node size is proportional to the number of accessions contained.

Fig. 2: Geographic distributions of the most frequent haplotypes of $P p d-H 1$ that are indicated in Fig. 1 and discussed in the text.

\section{Supplementary Tables}

Table S1: Details of landraces and wild barley accessions used in this study, and their source germplasm collections.

Table S2: SNPs in the 1,230 bp fragment of the Ppd-H1 gene. The position of each SNP is described by reference to GenBank accession AY970704.1: Hordeum vulgare subsp. vulgare cultivar Triumph pseudo-response regulator $P p d-H 1$. The most frequent haplotypes are indicated. The causative SNP is at position $2423 \mathrm{bp:} \mathrm{'C'}$ ' is the wild type allele at the Ppd-H1 gene, where flowering is promoted in response to long day photoperiods; ' $\mathrm{T}$ ' is the mutant type $p p d-H 1$ where flowering is not promoted by long day photoperiods. This is described in detail by Jones et al. (2008). 


\begin{tabular}{lllc}
\hline & $\begin{array}{c}\text { Number of } \\
\text { sequences }\end{array}$ & $\begin{array}{l}\text { Number of } \\
\text { Haplotypes }\end{array}$ & Haplotype diversity \\
\hline All accessions & 582 & 58 & 0.90 \\
Wild barley & 72 & 39 & 0.93 \\
Landrace Barley & 510 & 29 & 0.88 \\
\hline & & & \\
Frequent Haplotype & Frequency & Wild barley & Barley landraces \\
A & 0.16 & 6 & 85 \\
B & 0.11 & 1 & 65 \\
C & 0.19 & 2 & 109 \\
D & 0.07 & 1 & 38 \\
E & 0.09 & 8 & 44 \\
F & 0.04 & 1 & 22 \\
G & 0.12 & 0 & 68 \\
H & 0.02 & 0 & 11
\end{tabular}

Table 1: Ppd-H1 haplotype diversity among the wild barley accessions and barley landraces of the Old World and haplotype diversity for each of the frequent haplotypes described by Fig. 1. The haplotype diversity calculation is described in section 2.2. 


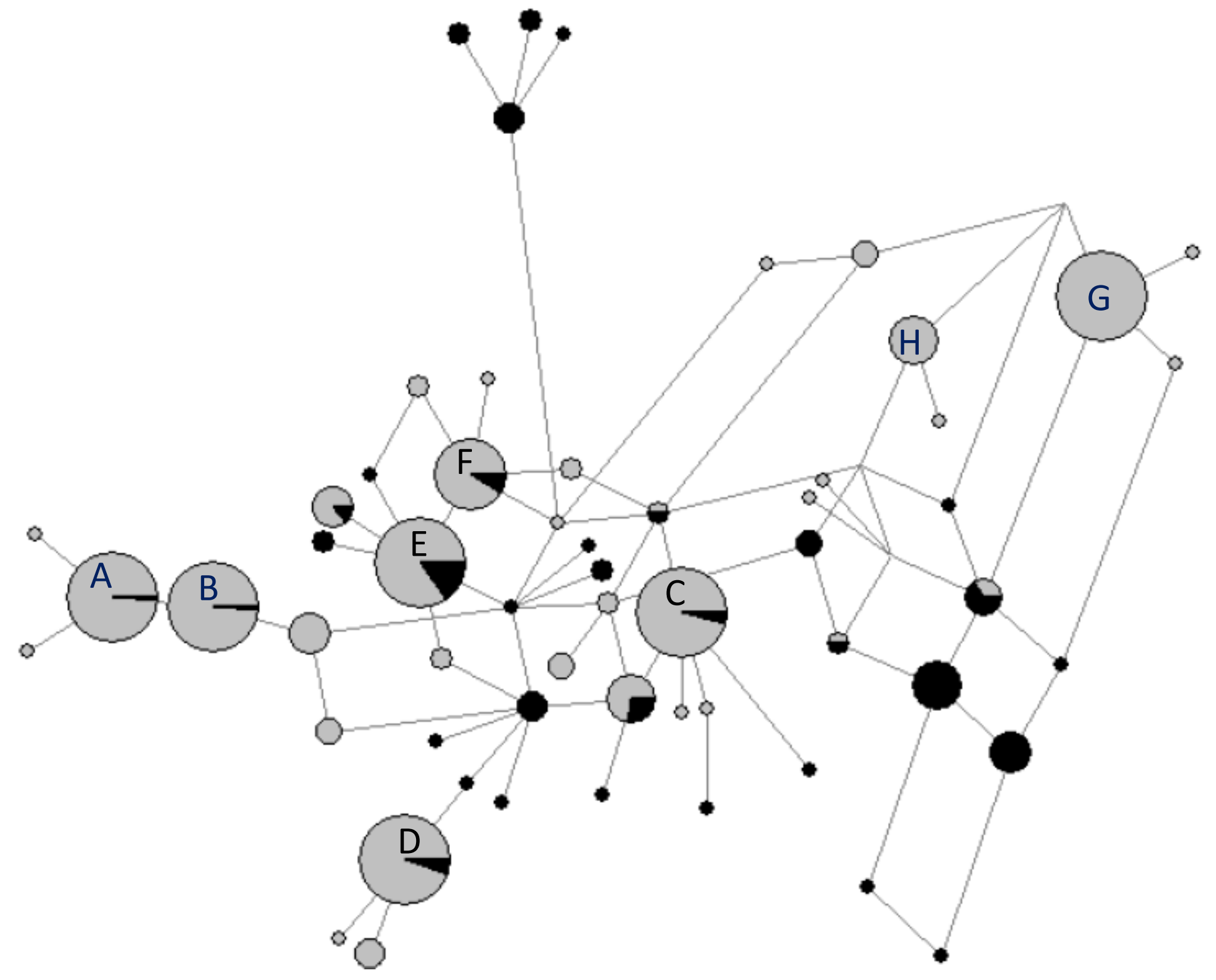




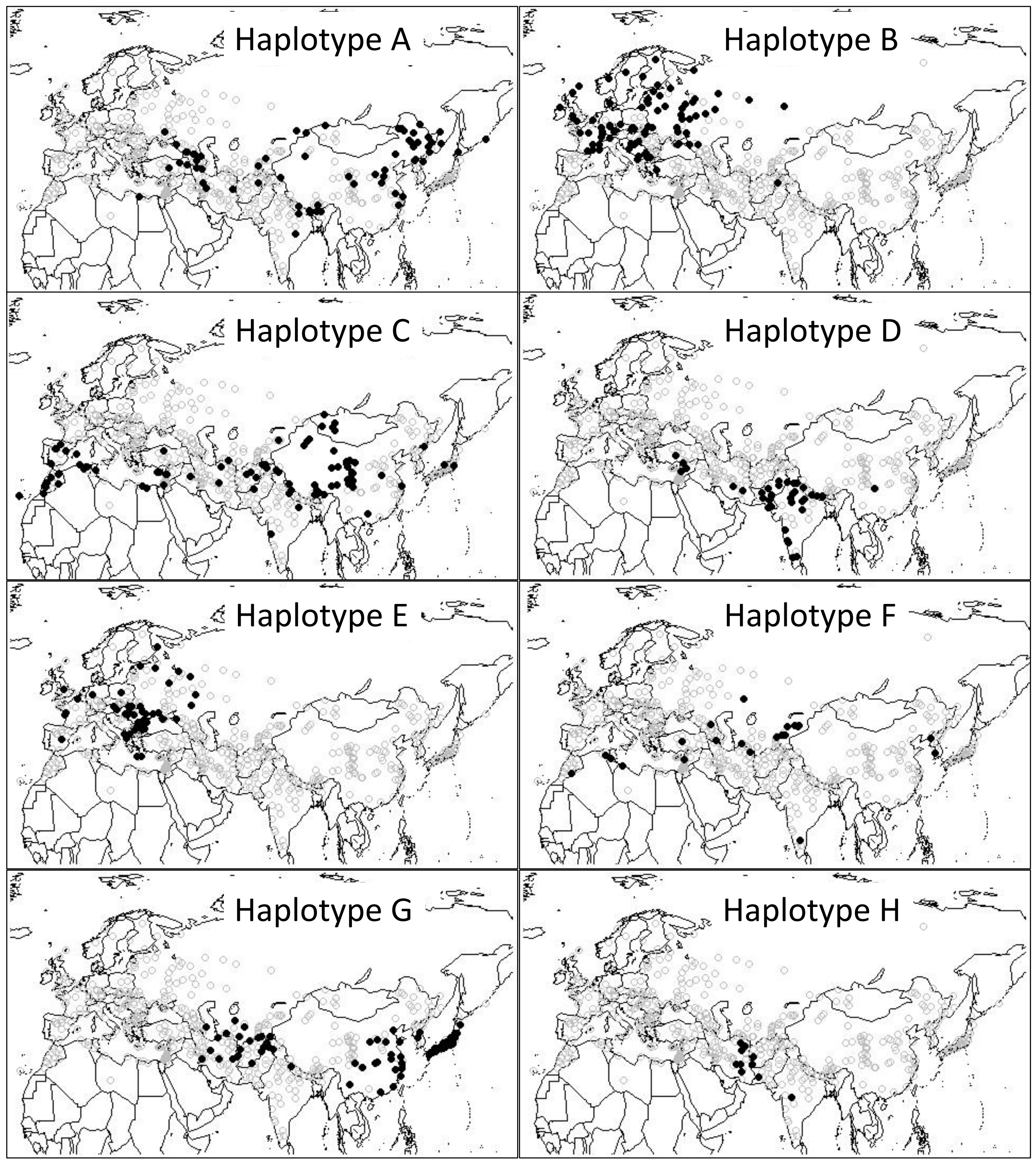


Source CodeGermplasm Collection

NSGC

IPK

RAC

INRA

JIC

NGB

SCRI

VAV

IRTA

ICARDA

PGR

FC
Leibniz Institute of Plant Genetics and Crop Plant Research

Federal Research Station for Plant Production Changins

French National Institute for Agricultural Research

John Innes Centre

Nordic Gene Bank

The James Hutton Institute

Vavilov Institute of Plant Industry

Investigacion Y Tecnologia Agroalimentaria

International Center for Agricultural Research in the Dry Areas

Plant Genetic Resources of Canada

Field Collection in China by X. Liu and M. K. Jones
City

Aberdeen

Gatersleben

Nyon

USA

Switzerland

Clermont Ferrand France

Norwich UK

Alnarp Sweden

Dundee UK

Saint Petersburg Russia

Barcelona Spain

Beirut Lebanon

Ontario Canada 


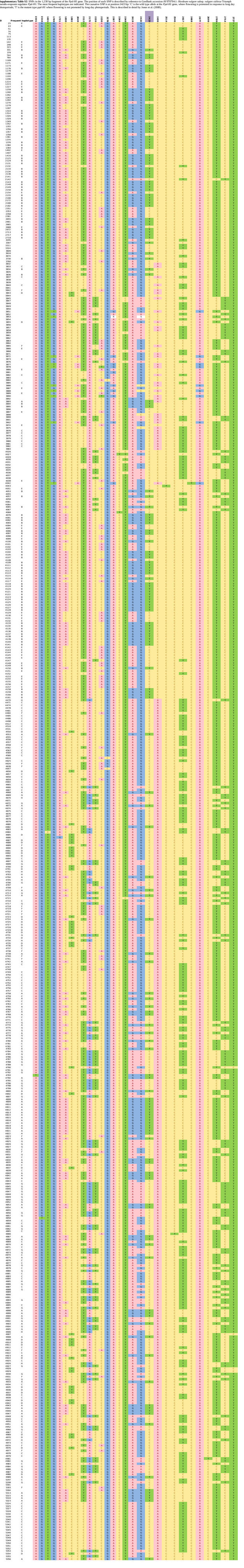




\section{Quaternary International}

We the undersigned declare that this manuscript is original, has not been published before and is not currently being considered for publication elsewhere.

We confirm that the manuscript has been read and approved by all named authors and that there are no other persons who satisfied the criteria for authorship but are not listed. We further confirm that the order of authors listed in the manuscript has been approved by all of us.

We understand that the Corresponding Author is the sole contact for the Editorial process. $\mathrm{He} / \mathrm{she}$ is responsible for communicating with the other authors about progress, submissions of revisions and final approval of proofs.

Signed by all authors as follows:
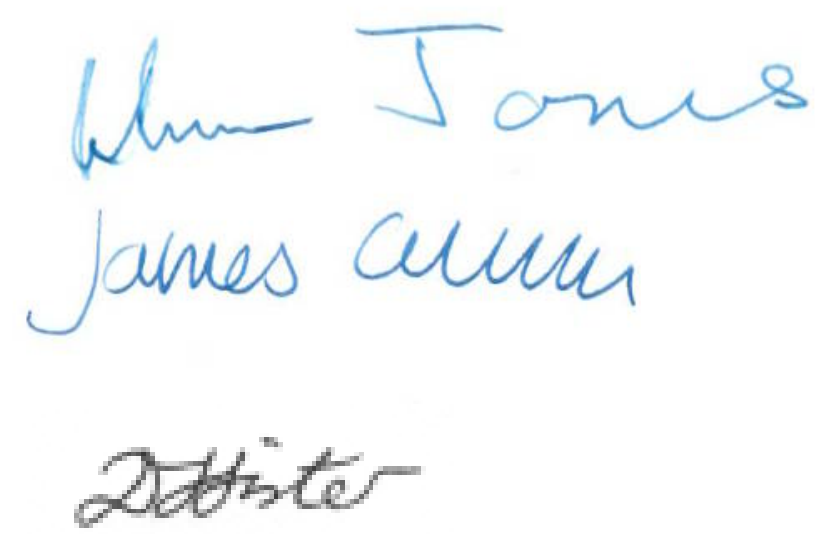


\section{Dear Professor Dodson,}

Further to your discussions with Prof. Martin Jones regarding the special issue of Quaternary International themed on 'Domestication of plants and animals in Eastern Asia and impacts on land-cover and prehistoric societies', we enclose a manuscript for your consideration.

Our paper 'The trans-Eurasian crop exchange in prehistory: discerning pathways from barley phylogeography' addresses the introduction of barley into eastern Asia. We use the phylogeography of a flowering time gene, photoperiod response 1 ( $P p d-H 1$ ), to draw conclusions on the dispersal of cereal agriculture from southwest Asia throughout the Old World. We discover population structures within dispersed barley landraces and describe their geographic distributions. We draw on published evidence from the archaeobotanical record to set these geographic distributions into their temporal context and draw conclusions on the dispersal processes that brought wheat and barley to East Asia.

Huw Jones

Diane Lister 